\title{
10 minutes with Sanjay Saint, Chief of Medicine, Veterans Administration Ann Arbor Healthcare System, Michigan, USA
}

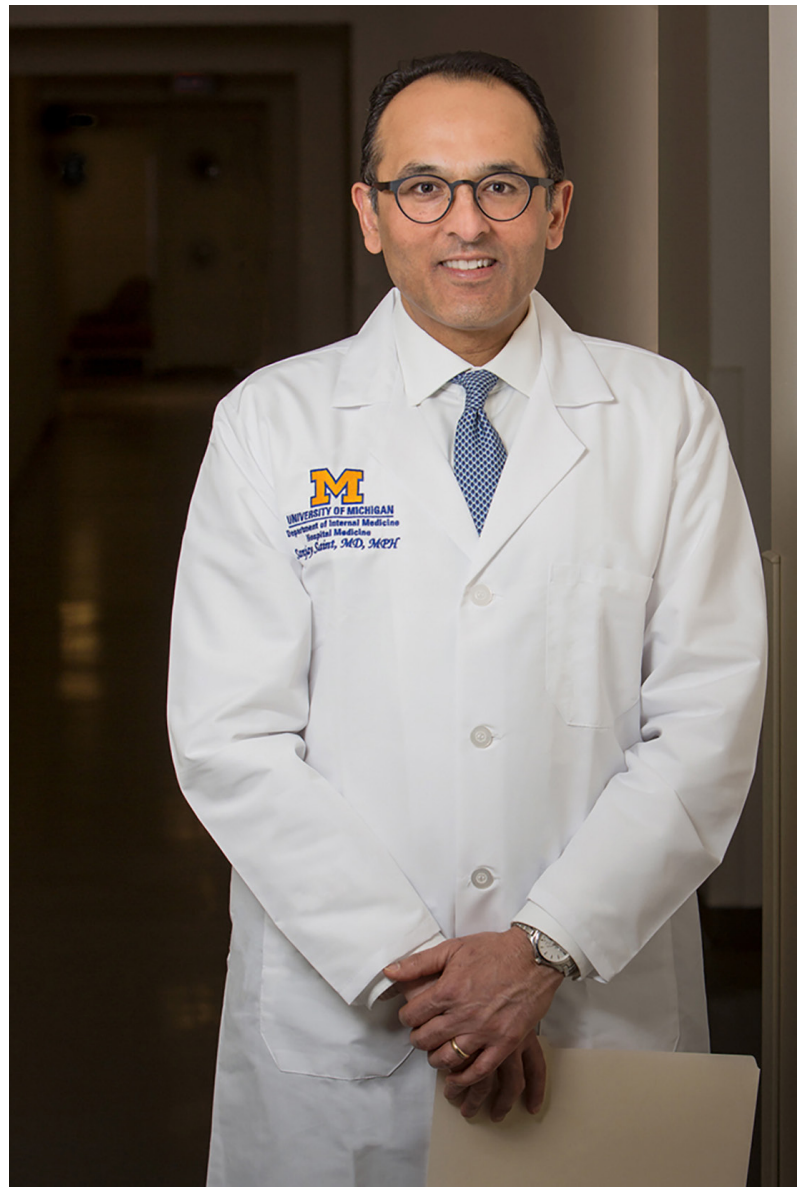

\section{WHAT ARE THE KEY LEADERSHIP MESSAGES YOU WANT TO GET OUT TO THE BMJ LEADER READERSHIP?}

The key leadership messages are mostly the same whether or not a pandemic is occurring. However, during a pandemic, adhering to several of the following becomes even more crucial since time seems compressed during urgencies. My key leadership messages are:

- Communicate but do not inundate. It is important to send out regular communications, usually via email. However, do not do these too frequently as it will be too much for the people in your Department or unit to handle and process. If possible, sending out regular emails will be something that your unit members may look forward to receiving and reading.

- Stay organised and focused. Time is your most precious commodity as a leader, now more than ever. Make lists of to-dos and check them off every day. Part of this requires you to learn how to toggle from a bird's-eye view to the worm's eye view and back again. Such zooming in and out is crucial. By staying too high level you will lose your ability to connect with the front line but staying "in the weeds" will lead to poor decision-making.

- Your most precious asset is your people. You need frequent contact and check-ins with your 'troops'. Some will be in person (albeit staying 6 feet away and wearing a mask). Others will be by phone or videoconferencing. If you find

\section{Biography}

Professor Sanjay Saint, MD, MPH, FRCP, is the Chief of Medicine at the VA Ann Arbor and the George Dock Professor of Medicine at the University of Michigan. He has authored over 375 peerreviewed papers, and serves on the editorial board of several peer-reviewed journals including NEJM Catalyst and BMJ Quality \& Safety. He is a Special Correspondent to the New England Journal of Medicine, and is an elected member of the American Society for Clinical Investigation (ASCl), and the Association of American Physicians (AAP).

He has coauthored three books published by Oxford University Press: 'Preventing Hospital Infections: Real-World Problems, Realistic Solutions', 'Teaching Inpatient Medicine: What Every Physician Needs to Know' and 'The Saint-Chopra Guide to Inpatient Medicine (4th Edition)'. In 2019 he received Mastership in the American College of Physicians (MACP). In 2017 he was awarded the Health System Impact Award from the Department of Veterans Affairs, and the Distinguished Mentor Award from the University of Michigan. In 2016 he received the Mark Wolcott Award from the Department of Veterans Affairs as the National VA Physician of the Year and was named an honorary Fellow of the Royal College of Physicians (FRCP).

that some of your faculty want to meet with you, try to oblige them if possible. Most of us despise meetings. Why? So many are an utter waste of time. But if some of your direct reports are asking for a meeting to discuss issueseither individually or as a group-pay attention to their request. They likely need important guidance and need to process issues beyond receiving an email with things to do.

- Roll up your sleeves. It is critical for leaders to be seen and heard from during times of stress. If the leader's presence is felt, not only does that help support staff-it helps leaders better understand the emotional and contextual issues that may surface.

- Delegate tactics, not strategy. The strategy is something that you need to develop. You must feel comfortable with it. Tactics, on the other hand, like how to do $\mathrm{x} / \mathrm{y} / \mathrm{z}$, is something that can be delegated.

\section{TELL US A LITTLE BIT ABOUT YOUR LEADERSHIP ROLE AND HOW IT IS CHANGING AS A RESULT OF THE PANDEMIC?}

I serve as the Chief of Medicine at the VA Ann Arbor Healthcare System. Our hospital is part of the largest integrated healthcare system in the country and one of the largest in the world with about 170 hospitals and 1000 clinics and other ambulatory care centres. The Medicine Service has approximately 360 staff which includes $\sim 160$ physicians and $\sim 200$ non-physicians (eg, respiratory therapists, nurses, administrators, dialysis technicians). The service is divided into 10 sections-including cardiology, pulmonary and critical care, hospital medicine, infectious diseases, geriatrics and oncology — each led by a section chief who is a physician. All of the physicians in the Medicine Service are faculty members at the University of Michigan Medical School. As COVID-19 is an acute respiratory tract illness, the patients admitted to the 
hospital-whether on the floor or in the intensive care unit-are cared for primarily by doctors and trainees in the Medicine Service. In terms of trainees, we have subspecialty fellows and house officers who work under the supervision of attending physicians, as well as physician assistants and nurse practitioners.

The COVID-19 pandemic has upended the usual workflow and clinical duties, especially in south-eastern Michigan, which is one of the national epicentres of COVID-19 cases. The State of Michigan has the third highest number of COVID-19 cases in the USA. Those of us at teaching hospitals have thrown out carefully prepared attending and learner schedules, and replaced them with an 'all-healthy-hands-on-deck' philosophy. At our own hospital, we had four resident teams: Burgundy, Gold, Silver and Yellow. Each resident team had one attending physician, one senior medical resident, two interns (sometimes a third if a psychiatry intern is rotating that month) and three to four medical students. Each team could care for up to 16 patients.

That was then, this is now.

Per guidance from the American Association of Medical Colleges, the medical students were removed from clinical duties on 17 March 2020; their return date is currently unknown. Our internal medicine residency instituted a new approach on 4 April 2020 during the COVID-19 surge in which the four resident teams will have one senior medical resident and one intern and be on a 1 week on/1 week off schedule. We also started a new team-Team 'Diamond'-on 1 April 2020 that manages the non-COVID-19 patients on a geographically isolated ward. Our model is one in which physician assistants-who usually care for patients in our subacute rehabilitation ward-and a geriatrics fellow will be overseen by attending physicians with complementary experience and expertise (eg, hospital medicine and geriatrics).

We have supplemented the single internal medicine intern on each team with interns from non-medicine clinical services such as dermatology and ophthalmology.

I have worked very closely with the leadership team in the Medicine Service to implement these changes in a very short time span. I also serve on our health system's COVID-19 Medical Task Force which oversees and coordinates key activities during this pandemic, such as personal protective equipment recommendations, testing protocols, bed utilisation and staffing.

\section{WHAT EVENTS IN YOUR PAST EXPERIENCE ARE MOST INFORMING YOUR LEADERSHIP IN THIS PANDEMIC?}

For the past several decades I have spent substantial time conducting health services research projects focusing on patient safety, medical education, clinical problem solving and leadership. My background as an investigator has been very useful during this pandemic as it has provided me with confidence that I can look at data and modelling predictions, and have an understanding of both the base case analysis and the sensitivity analyses. Much of my previous work has focused on understanding behaviour change among healthcare workers, which has included trying to get nurses and doctors to wash their hands in various countries such as the USA, ${ }^{1}$ Japan $^{2}$ and Italy, ${ }^{3}$ as well as focusing on removing unnecessary urinary catheters.

\section{WHAT ARE YOU FINDING THE BIGGEST CHALLENGES?}

My biggest personal challenge is focusing my energy on the things I can control and have responsibility for, rather than dwelling on aspects of this pandemic that are not under my direct controlsuch as the economic implications after this is over, what will happen to the hospital's finances and what downstream effects will this have on physicians and nurses, and their willingness to continue with front-line patient responsibilities.

The biggest job-related challenges are (1) being told different things by different people at different times; and (2) observing how some leaders, including senior-level executives, seem outmatched by events.

\section{ANY PARTICULAR SURPRISES?}

The biggest surprise is that some of the people that have volunteered for extra clinical duty are not the ones that I would have guessed. A distant second are those who I thought we could count on, who have gone into hiding.

\section{ARE YOU SEEING ANY BEHAVIOURS FROM COLLEAGUES THAT ENCOURAGE OR INSPIRE YOU?}

The volunteerism and openness to change has been incredible. We have been able to cut the red tape and bureaucratic delays in a manner I thought impossible before the pandemic. I have written about organisational constipators ${ }^{5}$ in the past; this pandemic is perhaps the most potent cathartic I have seen to get people to move forward with alacrity. It has taken less time for us to stand up three new inpatient medical teams than it usually takes to hang a picture in one of the faculty member's offices. I hope this will continue long after the pandemic.

\section{HOW ARE YOU MAINTAINING KINDNESS AND COMPASSION?}

I listen to spiritual music every morning as I head to work-and when I drive home. This has been a nice grounding exercise for me. I also try to pace myself, and make sure my team is pacing themselves, by suggesting telework schedules and taking needed breaks. As they say just prior to lift-off on a plane, during an emergency remember to put the oxygen mask on yourself before assisting others.

I also try to provide hope. The end of the regular emails should be uplifting but authentically so. Cheerleading is part of the job. It is important to thank people for stepping up. Both in emails and in handwritten notes. I try to make it a point to publicly thank people as much as possible and to use social media to laud them.

When I get frustrated by decisions with which I disagree, or with employees behaving in a non-constructive manner, I try to remind myself of the following: everyone is doing the best they can. Including me.

\section{WHAT ARE YOU LOOKING FOR FROM YOUR LEADERS?}

Consistent, reliable and trustworthy communication-both during meetings and via email-is one of the most important behaviours a leader can provide during times of crisis. This is what I want from my leaders and what I strive for in myself.

Sanjay Saint, ${ }^{1}$ Anthony Robert Berendt ${ }^{2}$

${ }^{1}$ Medicine Service, VA Ann Arbor Healthcare System, Ann Arbor, Michigan, USA ${ }^{2}$ Oxford, UK

\section{Correspondence to}

Dr Anthony Robert Berendt, Oxford, UK; a.berendt@ntlworld.com

Twitter Anthony Robert Berendt @tony_berendt

Funding The authors have not declared a specific grant for this research from any funding agency in the public, commercial or not-for-profit sectors.

Competing interests None declared.

Patient consent for publication Not required.

Provenance and peer review Not commissioned; internally peer reviewed. 


\section{0 minutes with...}

Data availability statement No data are available.

(c) Author(s) (or their employer(s)) 2020. No commercial re-use. See rights and permissions. Published by BMJ.

\section{Check for updates}

To cite: Saint S, Berendt AR. BMJ Leader 2020;4:144-146.

Received 15 April 2020

Accepted 22 April 2020

Published Online First 30 April 2020

BMJ Leader 2020;4:144-146.

doi:10.1136/leader-2020-000264

\section{REFERENCES}

1 Gilmartin H, Saint S, Rogers M, et al. Pilot randomised controlled trial to improve hand hygiene through mindful moments. BMJ Qual Saf 2018;27:799-806.

2 Sakihama T, Kayauchi N, Kamiya T, et al. Assessing sustainability of hand hygiene adherence 5 years after a contest-based intervention in 3 Japanese hospitals. Am J Infect Control 2020;48:77-81.

3 Saint S, Conti A, Bartoloni A, et al. Improving healthcare worker hand hygiene adherence before patient contact: a before-and-after five-unit multimodal intervention in Tuscany. Qual Saf Health Care 2009;18:429-33.

4 Saint S, Greene MT, Krein SL, et al. A program to prevent catheter-associated urinary tract infection in acute care. N Eng/ J Med 2016;374:2111-9.

5 Saint S, Kowalski CP, Banaszak-Holl J, et al. How active resisters and organizational constipators affect health care-acquired infection prevention efforts. Jt Comm J Qual Patient Saf 2009:35:239-46. 